\title{
A rare case of giant occipital encephalocele with craniosynostosis
}

\author{
Sibaji Dasgupta ${ }^{1}$, Suniti Kumar Saha ${ }^{2}$, Sunil Baranwal', Manpreet Singh Banga', \\ B V Sandeep ${ }^{1}$ \\ ${ }^{1}$ Post Doctoral Trainee, Department of Neurosurgery, Nilratan Sircar Medical College and Hospital, Kolkata, India, \\ ${ }^{2}$ Professor and Head, Department of Neurosurgery, Nilratan Sircar Medical College and Hospital, Kolkata, India
}

\section{A B S T R A C T}

Encephalocele and craniosynostosis are known separate entities found clinically. While searching for a causal association between them, there has been a proposed justified hypothesis. Yet the two conditions are very rarely found in association. We have happened to find such a rare case which we treated and followed up for establishing the proposed theory of association between the two clinical entities.

Key words: Encephalocele, Craniosynostosis, Association

\section{INTRODUCTION}

Encephalocele is herniation of cerebral tissue, meninges and Cerebrospinal fluid (CSF) in any combination outside the confines of the skull. It arises due to a defect in primary neurulation. On the other hand Craniosynostosis is premature closure of skull sutures leading to skull growth in a plane perpendicular to the plane of the fused suture. An Encephalocele is said to be giant when it 's size is larger than the head from which it arises. ${ }^{1}$ It's association with microcephaly is extremely rare. ${ }^{2}$ Apart from some systemic causes, a rare debatable neurosurgical cause for secondary craniosynostosis is chronic ventriculoperitoneal shunt overdrainage. ${ }^{3}$ Few cases of craniosynostosis have been described in association with neural tube defects (NTDs), but no efforts to establish a causal link among the two were made..$^{4-6}$ A proposed hypothesis suggested a causal relation between the two. $^{7}$ In our centre we report a case of a giant occipital encephalocele associated with compound synostosis which was operated and followed up.

\section{CASE REPORT}

A 7 month old male baby presented with a huge, soft swelling (Figure 1) of approximate size $35 \mathrm{~cm}$ x $20 \mathrm{~cm}$ over posterior aspect of head which was expansile on crying. Head circumference was $30 \mathrm{~cm}$. Computed tomography showed fusion of cranial sutures (Figure 2). Magnetic Resonance Imaging revealed a large meningo-encephalocele through a large defect in the occipital bone (Figure 3). Visual evoked responses were present in both the eyes.

\section{PROCEDURE}

The patient underwent staged operations. Strip craniectomy of coronal suture was done first followed by excision and repair of sac with strip craniectomy of sagittal with lambdoid suture(Figure 4) after a gap of 3 weeks.

\section{RESULT}

Post operative results after approximately 4 months showed an increase in head circumference by $5 \mathrm{~cm}$ with almost a complete disappearance of the swelling (Figure 5) without any new onset neurological deficit.

\section{DISCUSSION}

Studies in the literatures supporting the evidence of NTDs \& Craniosynostosis are a few. ${ }^{4-9}$ Martinez-Lage et $\mathrm{al}^{7}$ in their 


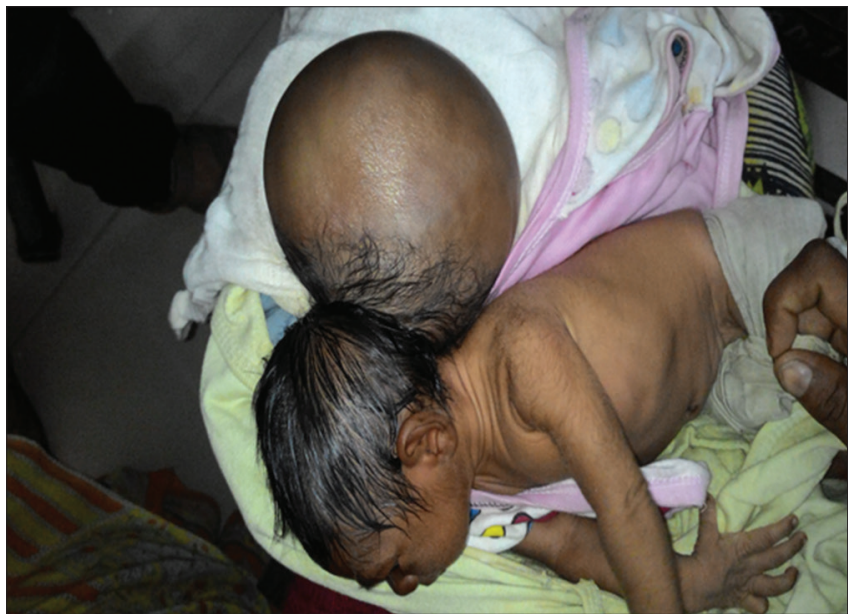

Figure 1: Huge soft swelling over posterior aspect of head

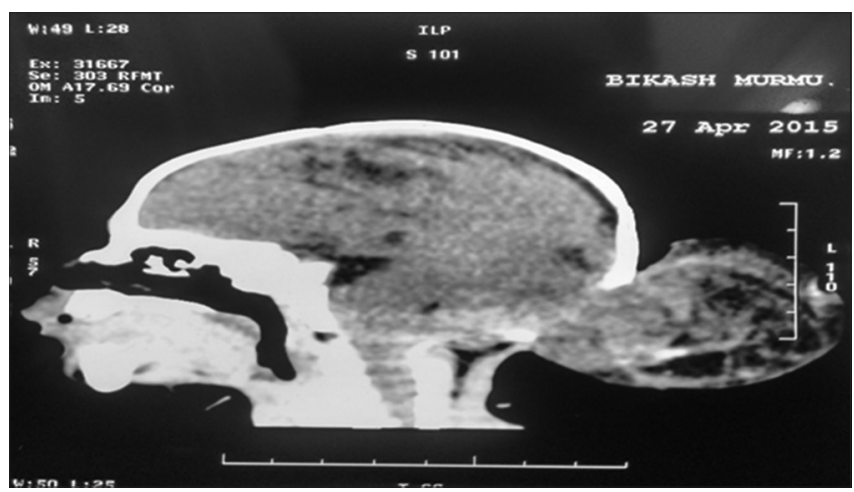

Figure 2: Fusion of cranial sutures on CT Scan of head

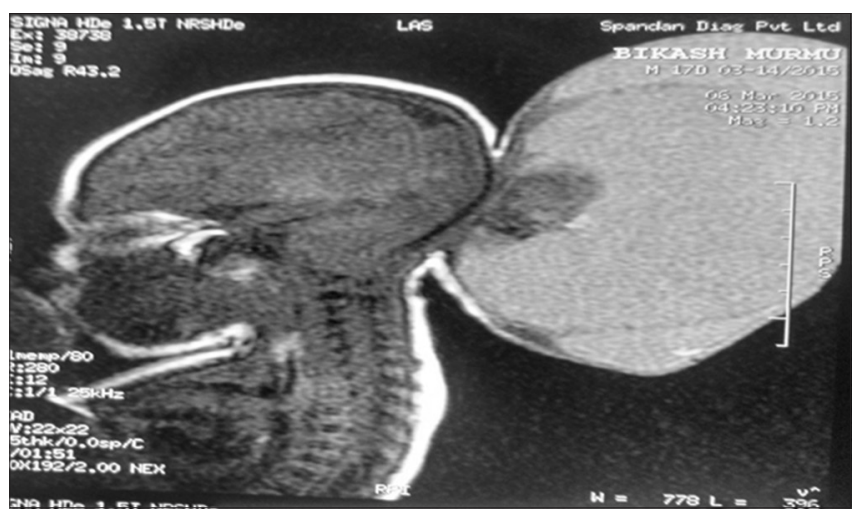

Figure 3: MRI showing meningoencephalocele in the occipital region

study concluded that this association of craniosynostosis with NTD is not coincidental and untreated NTD could induce the premature closure of some cranial sutures. They hypothesized that sacs of myelomeningocele and cephaloceles are able to accept large amounts of cerebrospinal fluid and their cavities act as compensatory mechanisms by diminishing intracranial pressure and pulsations that are necessary to stimulate normal brain and skull growth. Thus, a decrease in intracranial pressure caused by egress of cerebrospinal fluid and neural tissue

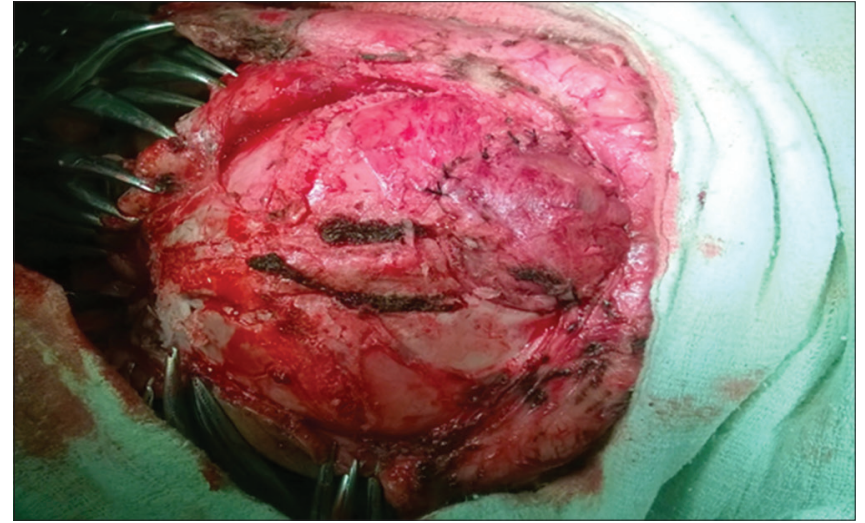

Figure 4: Excision and repair of sac with strip craniectomy

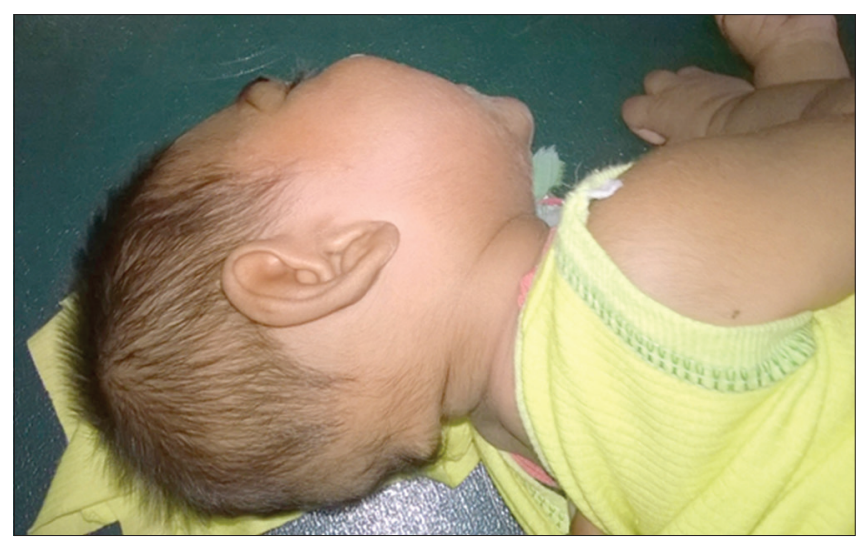

Figure 5: Post-op. results after four months showing increase in head circumference with complete disappearance of the swelling

inside the meningomyelocele/encephalocele sac may result in a deficient cerebral impulse for cranial growth that may stimulate premature sutural fusion.

\section{CONCLUSION}

In spite of having an acceptable proposed hypothesis, there has been debates whether to take that unanimously as we happen to get the two pathologies rarely in an association in our regular practice. In our longitudinal study, we found a definite increase in head size after decompression of the encephalocele. Hence, our study may support the causal relationship \& add to the further research in this aspect.

\section{REFERENCES}

1. Agrawal D and Mahapatra AK. Giant occipital encephalocele with microcephaly and micrognathia. Pediatr Neurosurg 2004;40:205-206.

2. Mealey J, Dzenitis AJ and Hockey AA. The prognosis of encephaloceles. J Neurosurg 1970; 32:209-218.

3. Hubballah MY and Hoffman HJ. Early repair of myelomeningocele and simultaneous insertion of ventriculo-peritoneal shunt: 
technique and result. Neurosurgery 1987; 20: 21-23.

4. Barrow $\mathrm{N}$ and Simpson DA. Cranium bifidum. Investigation, prognosis and management. Austr Paediat J 1966; 2: 20-26.

5. Gershoni-Baruch R, Nachlieli $T$ and Gilburd JN. Apert's syndrome with occipital encephalocele and absence of corpus callosum. Child's Nerv Syst 1991; 7: 231-232.

6. Waterson JR, Di Petro MA and Barr M. Brief clinical report. Apert syndrome with frontonasal encephalocele. Am J Med Genet 1985; 21 : 777-783.
7. Martinez-Lage JF, Poza M and Lluch T. Craniosynostosis in neural tube defects: a theory on its pathogenesis. Surg Neurol 1996; 46: 465-470.

8. Machado HR and Hoffman HJ. Long-term results after lateral canthal advancement for unilateral craniosynostosis. J Neurosurg 1992; 76: 401-407.

9. Borkar SA, Sarkari A and Mahapatra AK. Craniosynostosis Associated with Neural Tube Defects: Is There a Causal Association? Pediatr Neurosurg 2011; 47:337-341.

Authors Contribution:

SD: Designed the study, analysed the data, searched the literature, drafted and reviewed the manuscript, guarantor; SKS: Reviewed and edited the manuscript; SB: Reviewed and edited the manuscript; MSB: Searched the literature, designed the study; SBV: Reviewed and edited the manuscript

Source of Support: Nil, Conflict of Interest: None declared. 